As mentioned last week (p. 503), Herr Kritzinger, of Berlin, recently pointed out (Astronomische Nachrichten, No. 4rg8) that the radiant point of this comet was in $346^{\circ}+1^{\circ}$ on September 12 Mr. W. F. Denning informs us that he watched the skven September 10, 12, and 14, the weath peing mery clefr, but did not notice any meteoric ho from the point mentioned. There was an active radiant at $355^{\circ}+5^{\circ}$, however, about ten degrees E.N.E. from the position given by Herr Kritzinger. This display is often seen in September, and there is another at $346^{\circ}+x^{\circ}$ (exactly agreeing with the cometary radiant), often noticed both in August and September. The correspondence in the apparent places is probably accidental.

Mr. A. J. Hawkes writes from Bournemouth to suggest that the fing sunsets seen on Monday, and also at the end of last eek, may be due to meteoritic dust in the track of the comet recently crossed by the earth.

The Lowell Expedition to the Andes.-In a recent communication to Dr. W. J. S. Lockyer, Prof. David Todd briefly describes the location and work of the Lowell expedition to the Andes for the purpose of observing Mars under the best cgndition durfor the last opposition. Prof. Todd states that he slected CKina Alianza, in northern Chili, for the loczibu of the Amherst College r8-inch telescope, ghe he instruments sent out by Prof. Lowell, and has folnd the atmospheric condition most favourable. Cloudless skies obtained day and night, and a windless and steady atmosphere produced an average "seeing" of 4 on a scale of 5 . More than 5000 photographs, covering all regions of the planet, were obtained by Mr. E. C. Slipher, and many of them exhibit clearly the much discussed double canals. The telescope is the last one, of large size, erected by Messrs. Alvan Clark and Sons, and their chief mechanician, Mr. A. G. Ilse, is a member of the expedition. Photographs of the annular eclipse on July ro were also secured, and the ringless phase of Saturn was much observed and photographed. Prof. Todd removed the station to a point in the higher Andes above Limas during the first week in August.

Markings on the Third Satellite of Jupiter.-In No. 4199 of the Astronomische Nachrichten (p. 381,
September 6) Senor J. Comas Solá continues his description of the markings he has observed on Jupiter's third satellite, and gives position angles determining the positions of the same, at stated times, with regard to the direction of the axis of rotation of the planet. From the discussion of his rasults he concludes, provisionally, that ( $\mathrm{r}$ ) the visibility of theynorthern white cap is independent of the satellite's bsition in regard to the planet, and is incomparably greater than that of the other cap; its brightness is comparable to the snow-caps of Mars. (2) As on Mars, the northern cap of satellite III. is always bordered by a dark area, which appears darker nearer to the cap. (3) The northern cap appears to be turned towards us, and, if it is situated at the extremity of the axis of rotation of the satellite, the inclination of the equatorial plane to the orbit of the satellite must be considerable. (4) The dark spots and areas are difficult to observe, and appear to be variable in a very short time. (5) As yet nothing can be said of the rotation period of the satellite.

A plate of twelve drawings accompanies the paper, and shows very markedly the different features referred to, and their variations from time to time, as observed during the period November 24, 1906, to March 25, 1907.

Astrophysical Observations and Anomalous DisPERSION.-In Nos. 4197-8 (P, 34I, September 2) of the Astronomische Nachrichten, Prof 'Hartmann discusses at length the possible explanation of several thserved astrophysical phenomena by the theory of anomalous dispersion. $\mathrm{He}$ first discusses the general problem, and then its effect in the observed phorgena of the chromosphere, sun-spots, prominences, facu and flocculi, and the fixed stars. The results of the discussion are not universally conclusive, but Prof. Hartmann points out that, with stated conditions, the question may be decided by special observations. A bibliography of fifty-six papers on this subject is given at the end of the discussion.

\section{FORTY YEARS OF CORNISH MINING.}

$\mathrm{M} \mathrm{Y}$ connection with Cornish mining began in the year I867, when I succeeded the late Sir Clement (then. Dr.) Le Neve Foster as lecturer and assjstant secretary to Mr. Robert Hunt's Miners'. A fociatiof of Cornwall and Devon. It was a time of chention, for copper-mining after a brilyant garker of century or more was rapidly declining, fiff thinilg which though far more ancient had beconf secfond, in importance, was once more in the ascendant .The man-engine, the employment of which had been grfatly assisted a quarter of a century earlier by substantial prizes offered by the Royal Cornwall Poly. technic Society, was in use in a dozen of the principal mines, wire-rope and skip were gradually replacing chain and kibble, and rock-boring machines, thanks to the initiation of my predecessor, had already been practically tested in several parts of the county. These were real advances, but kibble-winding was still common even in the deepest mines; the cobbing hammer, the bucking iron, the hand-jigger, and the wooden shafted stamp were still at work to a large extent; while the stonebreaker, the California and pneumatic stamp, the various forms of pulveriser, the Frue and Luhrig vanners, the Wilfley and Buss tables, the self-acting and round slime frames, the air-compressor, and many other contrivances which are now looked upon as essentials in well-provided mines were only beginning to appear. When one compares the present condition of Cornish mining with its condition forty years ago, it is obvious that a sort of revolution has taken place.

In mining proper there has been no great advancement during the forty years. Somewhat greater depths have been attained in a few instances, and notably at Dolcoath, but Cornwall is still far behind several other mining regions in this respect. We are now more impressed than heretofore with the advantages afforded by good shafts, good underground roads, and good surface transport; the tramroad and tram-wagon have largely displaced the wheelbarrow; underground ore-bins, once so rare, are now becoming common; but in the main our system of underground mining was so good even a century ago that there was not very much room for improvement. Still, I will venture to predict that during the next forty years more vertical shafts will be sunk, that levels will be driven farther apart, that there will be a great deal more cross-cutting, and that our underground tramroads will be better constructed, so that "three men at a wagon" will be no more heard of.

As to the methods employed for breaking the ground, the chief changes have resulted from the use of boring machines and high explosives. In I868 I first saw Doering's machine at work in Tincroft Mine. It was not a success, for, being operated by steam, the workings were rendered almost unbearable ; in fact, while steam was the motive power, the use of the machine drill made very little progress either at home or abroad, and it is certain that if compressed air had not been introduced boring machines would to-day play a very small part in mining or tunnelling. Once introduced, however, the immense value of the system was at once recognised.

The difference between "to-day" and "yesterday" is seen in the fact that no rock-drill or air-compressor has ever been employed in the great mining parish of Gwennap, several of whose mines were still at work a generation ago, while at present all the great mines of the neighbouring parishes of Camborne and Illogan depend very largely upon these machines, not because they break the ground more cheaply, for it is well known that such is not the case (and, moreover, in narrow lodes they do not even break the ground more advantageously, for the " paystreak" inevitably becomes much contaminated with barren "country"), but because they open the ground more. speedily. One good effect of their employment has been the enlargement of the main drifts, and consequent improved ventilation, and this has been especially benefited by the large amount of cool exhaust air set free by the machines. The greater number of machine drills hitherto have been employed in sinking, rising, or drifting, but there is a constant and growing tendency to employ them in stoping also.

Forty years ago much gunpowder was still used in the- 
mines; to-day, after many experiments with compressed powder, cotton-powder, and other such compounds, and after nitro-glycerin had been tried and given up because of its danger, only such " high explosives" as dynamite, gelignite, and the. like are used. These high explosives only came into use ffter 'much experimenting, by the Royal Cornwall Polytechnic Society in particular, but they have proved themselves very serviceable, especially in hard ground, and they are also found to be much safer in use than the old black powder.

Great improvements have been effected in the machines used for compressing the air employed in woiking the machine-drills; compound engines, compressing the air in successive stages, are now generally employed in the larger mines.

Compound engines, mostly of the tandem type, were introduced into several Cornish mines by Mr. Sims more than half a century ago, but with the low-pressure steam then employed did not recommend themselves, and so went out of use. A compound engine using high-pressure steam has been employed for years past in pumping at the Basset Mines for working the ordinary force pumps; of late many attempts have been made to introduce centrifugal pumps operated by electricity for draining the mines: A certain measure of success has attended these efforts, particularly at the Tywarnhaile Mines, and more recently at Wheal Vor; but it must be admitted that up to the present the Cornish system of pumping, the rods being operated by a simple vertical engine, single acting in the case of large installations, holds the field.

The use of electricity is spreading in the Cornish mines apart from pumping. At East Pool it has long been employed for surface traction, the mill being a mile or more away from the mine. At South Crofty it is employed for operating the new stamp mill; in several mines it supplies power to work pulverisers, buddles, and other dressing machines, and in this direction-as also in electric lighting-there is a large field for extension.

There have been great improvements in the engines used for winding during the past few years. It no longer takes thirty to forty minutes to raise a kibble of stuff from the bottom of the deeper mines, as it did at one time; skips running between guides are now common, cages bringing the ore-wagons direct to surface are employed in several mines, while the men are mostly brought up from below in shaft-gigs or special skips, so that the man-engine, once so great a boon and used in no fewer than twelve mines, can now only be seen in operation in the Levant Mine. For modern winding wire-ropes are universally used, and are practically indispensable. Accidents from its use are, indeed, exceedingly rare. 'Mr. Morgan's traversing engine, erected some years since for hoisting from Williams's Shaft at Dolcoath, will soon be at work again, but so far no proposals seem to have been made for using this remarkable' engine anywhere else.

For signalling in shafts the old " knncker line." is still in use, and has its advantages. Indicators for the guidance of the engine-man are of course, placed in the engine house in every case where men are raised, and in most other cases; overwinding is an extremely rare occurrence, such is the carefulness of the engine-man. The telephone was introduced in Wheal Eliza by Dr. Le Neve Foster many years ago for signalling from below, but it did not "catch on." It is, of course, used for ordinary business purposes in several of the mines.

The steam-boilers used in Cornwall are mostly of the Cornish or Lancashire 'type, and work at comparatively low pressures. The number of these boilers working above 6olb. is not very great, and those working at 100 or more.could almost be counted on the fingers. Multitubular boilers, portable or semi-portable, are used in some in stances where good water is obtainable, and particularly for winding, while the electrical pumping plant at Tywarnhaile is worked by engines which consume " suction gas."

Many improvements have been introduced in the treatment of ores: the ores treated in Cornwall now are almost exclusively of tin, copper ore being rare, while the working of iron, lead, and zinc ores has practically ceased.

The first crushing is generally done by stonebreakers of the Blake type, followed by stamps of the Cornish, Caliईornia, or pneumatic type, the "rows" being finally reduced by some form of pulveriser. Self-feeders have not yet been used for the Cornish stamps, but they are always employed in connection with the California and pneumatic stamps. At Dolcoath powerful batteries of all three types can be seen regufardy at work.

For dressing the crushed ore, while'buddles ane still very generally used at some stages, Wilfley, Btiss, or other tables of the percussion type, or Frue vanners are employed in most of the larger mines. Hydraulic separators are mostly used to remove the slimes before feeding the pulp to the Wilfley and Buss tables, but in the case of the Frue vanner the slimes are generally removed for separate treatment at a later stage.

For slime treatment there is still nothing better known than the dead-frame, the ordinary round slime table, or the Acme table. The old-fashioned swinging rack for cleaning slime has practically disappeared, though it had some notable merits.

Most tin-ores need calcination before they can be cleaned for the market. In some of the smaller mines the old reverberatory oven is still in use, but in the larger mines the Brunton revolving calciner is always employed.

The calcination of tin-ores yields in some mines large quantities of " arsenic-soof,", which is collected in long flues of masonry; this soot, at one time. yalueless or worse, is now an important by-product. It is handled by the ton as freely as sand, and apparently with equal impunity for cases of arsenic poisoning are far rarer in Cornwall than in London. Another important by-product in some mines is wolfram, which at one time was merely a deleterious component of the dressed tin, but is now profitably extracted at many of the mines, and in particular at Clitters United, East Pool, and South Crofty by means of the Wetherill magnetic separator. In this machine the powdered and thoroughly dried concentrates are carried slowly over electro-magnets on traversing belts. The magnets remove the slightly magnetic particles of wolfram, while the non-magnetic particles of cassiterite pass on and fall into a separate receptacle. The wolfram so separated in most cases still contains a considerable percentage of tin-oxide. At the mines mentioned this tin-wolfram product is "pickled" with dilute acid (aided by jets of steam at East Pool) in order to remove certain highly magnetic iron oxide components, which seriously interfere with the operation of the magnetic separator. A similar "pickling" was recommended by Dr. Richard Pearce forty years ago, and has occasionally been used for the removal of copper from calcined tin ores.

At Tynwarnhaile, and also at Dolceath, the Elmore oil processes have been, or are being, introduced for the concentration of low-grade copper ores. The wet ore-pulp is mixed with oil and subjected to a partial vacuum, by which means the ore-particles are floated up from the waste as a sort of mineral scum, which is readily separated from the waste, and with much less loss than is the case by the methods hitherto employed.

Enough has been said in this hasty summary to show that the Cornish miner to-day, as in the past, is very ready to avail himself of such new methods and appliances as have a reasonable prospect of success, although it must be admitted that he is rather fond of letting other people experiment for his benefit. J. H. Collins.

\section{THE IRISH PEAT INDUSTRIES. ${ }^{1}$}

$A$ CCORDING to reports published in $18 \mathrm{I}_{4}$ by the Bog A Commissioners Ireland possesses 3,028,000 acres of "peat bog," of whith $\mathrm{r}, 648,000$ acres form "available"

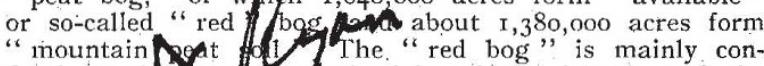
fined to th greal cen plain of the island, and the "mountai Nbg " to the counties of Wicklow, Donegal, Mayo, Galway, and Kerry. As the sccompanying outline bog map (Fig. I) shows, there are few portions of the island destitute of bog.

The slow but continuous reclamation of Irish bogs which has been going on for the past three hundred years is referred to in a work written, in .1645, by Dr.

1 Abridged from the Economic Proceedings cf the Royal Dublin Society, vol. i., part $x$. (July) 